Full Length Article

\title{
Unraveling scientific impact: Citation types in marketing journals
}

\author{
Stefan Stremersch ${ }^{\mathrm{a}, \mathrm{b}, *}$, Nuno Camacho $^{\mathrm{a}}$, Sofie Vanneste ${ }^{\mathrm{c}, 1}$, Isabel Verniers ${ }^{\mathrm{c}}$ \\ a Erasmus School of Economics, Erasmus University Rotterdam, the Netherlands \\ b IESE Business School, University of Navarra, Spain \\ c Ghent University, Belgium
}

\section{A R T I C L E I N F O}

\section{Article history:}

First received in February 16, 2013 and was

under review for $4 \frac{1}{2}$ months

Available online 12 October 2014

Area Editor: Ajay Kohli

Guest Editor: Donald R. Lehmann

\section{Keywords:}

Science

Citation

Scientometrics

Philosophy of science

Marketing

Innovation

\begin{abstract}
A B S T R A C T
The number of citations a paper receives is the most commonly used measure of scientific impact. In this paper, we study not only the number but also the type of citations that 659 marketing articles generated. We discern five citation types: application, affirmation, negation, review and perfunctory mention (i.e., citing an article only indirectly without really using it). Prior literature in scientometrics recognizes that the former three types, on average, signal a higher level of scientific indebtedness than the latter two types. In our sample, these three types of citation represent only $15 \%$ of all citations. We also find different determinants of citation behavior across citation types. Across the 49 determinants we included, only 13 have the same effect across all citation types, of which only 5 are statistically significant across all citation types. For instance, we find a significant inverted U-effect of challenging commonly held beliefs on citation counts, but only for three of the citation types: affirmation, review and perfunctory mention. Our results encourage scientific stakeholders to move beyond mere citation counts to assess a paper's or a scholar's scientific contribution, as well as to devote greater attention to the citation process itself.
\end{abstract}

(c) 2014 The Authors. Published by Elsevier B.V. This is an open access article under the CC BY-NC-ND license (http://creativecommons.org/licenses/by-nc-nd/3.0/).

\section{Introduction}

The pursuit of scientific impact is of pivotal importance for scholars. The most commonly used measure of scientific impact of an article is the number of citations it receives (e.g. Egghe, 2006; Hirsch, 2005, 2007; Radicchi, Fortunato, \& Castellano, 2008; Stremersch \& Verhoef, 2005; Stremersch, Verniers, \& Verhoef, 2007). Citation counts - the number of publications that list the cited article in their bibliographies - are often used to measure the stature of journals and scholars (Lehmann, McAlister, \& Staelin, 2011). However, not all citations may signal the same level of intellectual indebtedness towards the cited article (Garfield, 1972; Woolgar, 1991). Papers may be cited for different reasons. While some citations

\footnotetext{
We are indebted to the participants of the Informs Marketing Science and EMAC Conferences, and to the seminar participants at Erasmus University Rotterdam, BI Norwegian Business School, and the University of Stavanger for all the valuable suggestions. The usual disclaimer applies.

* Corresponding author at: Burg. Oudlaan 50, room H15-09, 3062 PA Rotterdam, the Netherlands. Tel.: +31 104081303 ; fax: + 31104089169.

E-mail addresses: stremersch@ese.eur.nl (S. Stremersch), camacho@ese.eur.nl (N. Camacho), sofiejulie.vanneste@ugent.be (S. Vanneste), isabel.verniers@ugent.be (I. Verniers).

${ }^{1}$ Data collection for this project was done by Sofie Vanneste when she was a doctoral student at the Ghent University. An earlier version of this paper was included in Sofie Vanneste's dissertation. At the time of publication, Sofie Vanneste is a consultant at WES, Brugge, Belgium.
}

indicate a fundamental influence of the cited article on the citing article, other citations reflect indirect mentions of articles that the authors did not really use in their paper (Moravcsik \& Murugesan, 1975).

These concerns have led to two types of research that go beyond mere citation counts in order to understand scientific impact better (for a detailed review, see Bornmann \& Daniel, 2008). A first type examines citation motivations through surveying and interviewing scholars (for examples, see Brooks, 1985; Case \& Higgins, 2000; Shadish, Tolliver, Gray, \& Sengupta, 1995; Vinkler, 1987). A second type of research, more limited in scope and size, content analyzes citing articles and describes the frequency of different types of citations. Studies in this second literature stream typically involve a limited number of cited articles (in several occasions only one cited article is studied) and a limited number of citing articles (for examples, see Anderson \& Sun, 2010; Krampen \& Montada, 2002; Moravcsik \& Murugesan, 1975). Therefore, there has been limited generalizable empirical research that content analyzes the citations papers receive and most research infers scientific impact from proxies such as a mere overall count of citations.

Our present study provides the first large-scale examination (24,632 citing articles) of citation types, their frequencies and their determinants. We discern five citation types (based on Baumgartner \& Pieters, 2003): application, affirmation, negation, review and perfunctory mention. Application citations occur when the 
citing article directly uses a concept, technique or theory of the cited paper. Affirmation citations occur when the citing article provides support for the cited article. In case of negation, the citing article rejects conclusions of the cited article. Review citations occur when an article is cited to show what prior literature has studied. Perfunctory mentions occur when authors cite an article only indirectly without really using it.

Scholars in scientometrics have for long argued that these different types of citation may signal different levels of scientific impact (Chubin \& Moitra, 1975; Frost, 1979; Moravcsik \& Murugesan, 1975). They view affirmation, application, and negation citations as signaling a higher level of intellectual indebtedness towards the cited article than review cites and perfunctory mentions. Application and affirmation citations signal scientific recognition of earlier insights and may serve as structural building blocks for scientific evolution (Merton, 1988; Small, 2004). Negation cites also contribute directly to academic inquiry by highlighting theories or concepts that need revision and are "a form of credit that legitimizes one's contribution" (Baldi, 1998; p. 829). Review citations may clarify the scope or contribution of the citing article or justify the citing article. Hanney et al. (2005) suggest that review citations are mainly used to compare the citing article with other relevant articles and are typically of peripheral or limited importance to the citing paper (rather than of considerable or essential importance). Perfunctory mentions, by definition, do not signal scientific merit from citing to cited article and their inclusion lacks a scientific rationale (Baumgartner \& Pieters, 2003; Moravcsik \& Murugesan, 1975; Small, 2004).

To examine to what extent the determinants of citation behavior are different across citation types, we lean on a comprehensive framework introduced by Stremersch et al. (2007). We also extend that literature on determinants of citation behavior and content-code all 659 cited articles in our study on the extent to which an article challenges commonly held beliefs. In a classic paper on philosophy of science, Murray Davis (1971) argues from a content perspective that theories that challenge commonly held beliefs are the most impactful. Also, in marketing and management, editors and authors have stated that publishing papers that deliver unexpected insights is the ultimate goal for journals and authors (e.g. Bartunek, Rynes, \& Ireland, 2006; Dekimpe, 2009; Huber, 2008; Shugan, 2003; Smith, 2003; Stremersch \& Lehmann, 2009). We are the first to content-code articles on the extent to which they challenge commonly held beliefs and can therefore test whether challenging commonly held beliefs leads to higher citation counts and, if yes, of which type.

The effect is not straightforward to predict. On the one hand, a paper that challenges commonly held beliefs may be more memorable, develop new research streams or generate excitement about an area of research, possibly increasing the citation potential of such papers (Davis, 1971). On the other hand, scientists often resist or try to ignore new discoveries that challenge their existing theories (Barber, 1961; Kuhn, 1996). Even notable scientists like Newton, Mendel, Galton, Planck or Einstein faced resistance and intolerance by peers of their time before their breakthroughs ultimately became well accepted (Mahoney, 1979). Scholarly resistance may lead scientists to dismiss papers that challenge commonly held beliefs, limiting their citation potential.

Our sample consists of 659 cited articles randomly drawn from five major marketing journals, International Journal of Research in Marketing (IJRM), Journal of Consumer Research (JCR), Journal of Marketing (JM), Journal of Marketing Research (JMR), and Marketing Science (MKS), balanced across years, journals and volumes over the time period 1990-2007. These journals are a good representation of the marketing discipline (Stremersch et al., 2007). In the marketing discipline, there has been a spur of interest in the citation outcomes of scholarship, at the level of the journal (Stremersch \& Verhoef, 2005), article (Berger, 2009; Sawyer, Laran, \& Xu, 2008;
Stremersch et al., 2007; Yadav, 2010), research topic (Kunz \& Hogreve, 2011), and author (Seggie \& Griffith, 2009). Other management fields have seen a similar interest (e.g., Borokhovich, Bricker, \& Simkins, 1994; Judge, Cable, Colbert, \& Rynes, 2007; Mingers \& Xu, 2010).

The analysis of citation types yields several unique insights. In our sample, $31.8 \%$ of all citations are perfunctory mentions, $52.9 \%$ are review citations and only $15.3 \%$ of all citations are application, affirmation and negation citations. We also find different determinants of citation behavior across citation types. We find an inverted-U relationship between challenging commonly held beliefs and citation counts and between challenging commonly held beliefs and three of the citation types: affirmation, review and perfunctory mention. The highest number of citations occurs for a paper with a moderately high level of challenging commonly held beliefs.

Across the remaining 47 determinants of citations, only 13 have the same effect across citation types, of which only 5 are statistically significant across all citation types. We find, for instance, that articles of editorial board members receive more perfunctory mentions than articles of non-editorial board members, while the effect of editorial board membership on total citations is insignificant. We also find that the number of references in an article is positively related to the article's total citation count, but that this effect is entirely due to perfunctory mentions. The number of co-authors has a positive effect on application citations, while its effect on total citations and other citation types is insignificant.

These results suggest that inference on impact based solely on overall number of citation counts is problematic. Mere citation counts may not represent the true scholarly impact of an article or author. Moreover, we find that perfunctory mentions may be inflated by gaming in the review and citation process. These insights have important implications for several scientific stakeholders. For instance, journal editors should devote more attention to the frequent occurrence of cites that do not represent scientific merit from citing to cited article. Policies editors could put in place include raising more awareness among reviewers and authors about perfunctory citations and making reviewer assignment independent of the authors' referencing behavior.

To evaluators of scientific merit - such as business school administrators and peer review committees - we can conceive at least three implications. First, citation counts are a noisy measure of a scholar's scientific proficiency and, therefore, administrators should be cautious when using this metric to rank and compare scholars. While large differences between scholars (e.g. a scholar with 100 citations versus one with 1000 citations) are indicative of variations in impact, small differences may be caused by mere measurement noise. Second, administrators should avoid comparing citations across (sub)fields. There are important differences in popularity and citation practices across subfields, as documented by the significance of method type and subject area in our citation regressions, which cast doubt on the validity of such comparisons. Finally, scientific influence is a complex construct that depends not only on the number of citations a paper generates, but also on the types of citation it generates and on other indicators of scholarly impact. Thus, a multidimensional view of scientific impact is preferable, possibly using a balanced scorecard that considers several drivers of impact.

\section{Theoretical background}

\subsection{Citations}

The number of citations refers to the number of times that all publications in a population list the cited article in their bibliographies. There are two common populations. The first population is all ISI (Institute for Scientific Information, now part of Thomson Reuters) journals. The 
second population is all on-line resources across which one can archive through Google. The latter population is much larger than the former, but also more amenable to manipulation and noise (Goldenberg, Libai, Muller, \& Stremersch, 2010; Lehmann et al., 2011). The reason is that the majority of on-line resources do not have a review process that is customary for ISI-covered journals, which are all peerreviewed (Garfield, 1990).

Several authors have offered a comprehensive view on drivers of citations. Stremersch et al. (2007) organize drivers of citations according to three perspectives: universalism, social constructivism and presentation. Bergh, Perry, and Hanke (2006), Judge et al. (2007), Mingers and Xu (2010), and Van Dalen and Henkens (2001) show that author characteristics, article characteristics and research methodology predict the impact of an article.

In addition, publication outlet and time of publication affect citations. Scientists are more likely to cite papers published in top tier journals than papers published in journals of lower rank (Judge et al., 2007; LaBand, 1986; Van Dalen \& Henkens, 2001). Older articles had more time to collect citations than younger articles (Bergh et al., 2006; Judge et al., 2007). The population of articles may increase over time, because new journals appear or existing journals publish more articles. In consequence, the number of citations typically increases over time. Scholars have also argued that strategic considerations by the author(s) in the publication process may drive their citation behavior (Bauerly, Johnson, \& Singh, 2005; Baumgartner \& Pieters, 2003; Tellis, Chandy, \& Ackerman, 1999). For instance, authors may excessively cite the editor or potential reviewers.

\subsection{Citation types}

According to Baumgartner and Pieters (2003), citations can be classified in five citation types: (1) application, (2) affirmation, (3) negation, (4) review and (5) perfunctory mention. ${ }^{2}$ Application citations occur when authors cite an article because they use its findings, methods or concepts. For instance, Narasimhan, Neslin, and Sen (1996) apply the PromotionScan methodology of Abraham and Lodish (1993). Affirmation citations occur when authors cite an article because their results confirm the findings of the cited study. Leonidou, Katsikeas, and Samiee (2002) support the findings of Samiee and Anckar (1998) that active exporters use foreign currencies more often than reactive exporters. Negation citations occur when authors cite an article because they critique, attack or disconfirm the cited study. Wang (2004) finds that return policies do not intensify retail competition, in contrast to Padmanabhan and Png (1997). Review citations occur when authors cite an article to illustrate what prior literature has studied. Griffith and Lusch (2007) use Wotruba and Tyagi (1991) as a representative example of the literature on job outcome constructs. Perfunctory mentions occur when authors cite an article only indirectly without really using it. Rindfleisch, Malter, Ganesan, and Moorman (2008) examine the role of longitudinal surveys and list Erdem, Swait, and Valenzuela (2006) as an example where a non-longitudinal survey has been employed.

Scholars in scientometrics have for long argued that different types of citation may signal different levels of scientific impact (Chubin \& Moitra, 1975; Frost, 1979; Moravcsik \& Murugesan, 1975). They consider affirmation, application, and negation citations as signaling a higher level of intellectual indebtedness towards the cited article than review cites and perfunctory mentions. Application and affirmation citations signal scientific recognition of earlier

\footnotetext{
2 Note that, compared to the original paper of Baumgartner and Pieters (2003), we collapse use/application under the term "application" and the term affirmation/support under "affirmation", for brevity.
}

insights and may serve as structural building blocks for scientific evolution (Merton, 1988; Small, 2004). Affirmation citations reflect scientific indebtedness because the cited paper confirms the correctness of the cited paper (Moravcsik \& Murugesan, 1975). Application citations reflect scientific indebtedness through the direct usage of a concept, technique or theory proposed by the citing paper (Moravcsik \& Murugesan, 1975). Negation cites contribute to academic inquiry by highlighting theories or concepts that need revision and are "a form of credit that legitimizes one's contribution" (Baldi, 1998; p. 829). Review citations may clarify the scope or contribution of the citing article or justify the citing article. While such citations may be scientifically appropriate, they are less likely to represent high scientific merit (Bornmann \& Daniel, 2008; Chubin \& Moitra, 1975). Perfunctory mentions, by definition, do not signal scientific merit from citing to cited article and their inclusion lacks a scientific rationale (Baumgartner \& Pieters, 2003; Moravcsik \& Murugesan, 1975; Small, 2004).

\subsection{Determinants of citation behavior}

In line with Stremersch et al. (2007), we organize determinants of citations according to three perspectives: universalism, social constructivism and presentation. In the universalist view, article quality predominantly drives citations (Cole \& Cole, 1973; Van Dalen \& Henkens, 2001). The domain of the article may also affect its citation count beyond quality (Bettencourt \& Houston, 2001).

In the social constructivist perspective, a scientist's status and background drive citations. Merton (1968) popularized social constructivism as the Matthew effect in science. The contributions to science by scholars of acknowledged standing are more visible than the contributions by scholars of lower standing. Therefore, paraphrasing the Gospel of Matthew, Merton (1968) argued that scientists that have accrued more citations will get even more. Other social constructivist determinants of citations may include the author's publication history and the author's affiliation (Judge et al., 2007) and a scholar's visibility and personal promotion (Stremersch et al., 2007).

In the third perspective, the manner in which science is presented drives citations. Think of title length, the use of attention grabbers in the title and expositional clarity, such as readability, number of tables and figures, number of footnotes, number of keywords, number of appendices and number of equations (Stremersch et al., 2007).

We extend the literature on determinants of citation behavior by examining the extent to which papers challenge commonly held beliefs. Papers that challenge commonly held beliefs deny an aspect of the assumption-ground of its audience (Davis, 1971). They typically have a structure, such as: "What seems to be $X$ is in reality non-X" or "What is accepted as X is actually non-X". Such articles engage readers' attention by attacking what readers have traditionally assumed as true (Davis, 1971; Smith, 2003). The work of Davis (1971) has been very influential (Bartunek et al., 2006) and is often included in doctoral education programs in marketing. ${ }^{3}$

Once published, challenging commonly held beliefs may influence the number of citations a paper receives. However, two contradictory predictions can be made, depending on how the level of challenge to commonly held beliefs affects the capacity of an article to spark curiosity and attention versus resistance to the ideas proposed therein.

On the one hand, some scholars suggest that papers that challenge widely held beliefs may be cited more frequently because they spark

\footnotetext{
${ }^{3}$ We conducted a survey among a convenience sample of marketing academics and doctoral students (ELMAR; AMA DocSig). 59 respondents from 28 universities participated (some respondents belonged to the same institution). This survey revealed that, in $69 \%$ of the cases, the respondent's school includes the Davis (1971) article in their doctoral education.
} 
greater curiosity and attention from their audience (Colquitt \& George, 2011; Hidi, 1990). Curiosity and attention may motivate readers to immerse and explore the novel information presented in a paper and make them more willing to think in new ways (Kashdan \& Silvia, 2009), possibly stimulating follow-on research that fine-tunes and extends the original breakthrough (Abelson, 1995). According to this view, challenging commonly held beliefs may therefore yield a higher citation count.

On the other hand, vested scientists typically interpret the first challenge to commonly held beliefs as an anomaly, which they easily discredit and ignore (Kuhn, 1996). In Kuhn's own words (1996, p. 65): "In science ... novelty emerges only with difficulty, manifested by resistance, against a background provided by expectation." Scholars' tendency to ignore papers that challenge commonly held beliefs may be hardwired in the human brain. For instance, confirmatory bias - one's tendency to overweight confirmatory and underweight disconfirmatory evidence - may lead scholars to depart from scientific ideals such as objectivity and neutrality, and trigger resistance (Mahoney, 1979). According to this view, challenging commonly held beliefs may therefore yield a lower citation count.

Combining the attention and the resistance arguments, we expect a curvilinear relationship between challenging commonly held beliefs and citations, in which papers with a moderate level of challenging commonly held beliefs have the greatest citation potential. A paper with a moderately high level of challenging commonly held beliefs is able to spark significant curiosity and attention among its target audience. At the same time, such a paper does not cross a threshold level of challenge to the assumption-ground of its audience that would lead it to be considered an anomaly, making the paper harder to ignore and dismiss.

\section{Data}

\subsection{Data collection procedure}

We randomly sampled 659 articles balanced across years, journals and volumes over the time period 1990-2007. The final sample contained 88 articles from IJRM, 141 articles from JCR, 143 articles from JMR and MKS and 144 articles from JM. There are fewer IJRM articles in the final sample because IJRM only entered the Institute for Scientific Information's (ISI, now part of Thomson Reuters) Social Sciences Citation Index (ISI-SSCI) in 1997. These five journals are a good representation of the marketing field (Stremersch et al., 2007). We excluded editorials, book reviews and articles without marketing theory ${ }^{4}$ ( $7 \%$ of the full sample).

\subsection{Variables}

\subsubsection{Citations}

One of the authors gathered cumulative ISI citation counts until the end of 2009, from the Web of Science, in the fall of 2010. Thus, articles in our sample had more than two years of citation opportunity.

\footnotetext{
${ }^{4}$ Articles without marketing theory are articles of a purely methodological nature. For instance, Rossi and Allenby (1993) present a Bayesian approach to the estimation of household parameters and discuss algorithms that can be used to maximize likelihood functions. Because there are no theory propositions, hypotheses or empirical findings, such a paper cannot challenge prior theories. In this paper, we focus on challenging existing theories, not of methodological approaches, which also fits Davis (1971) origina work. Note however that this does not mean we exclude all methodological papers. Stateof-the-art papers in terms of methodology which address substantive issues and test hypothesized effects are still included in our sample. For instance, Dekimpe and Hanssens (1999) argue that marketing resources should be allocated for their long-run impact. They then propose a modeling approach, using VAR models and impulse response functions and use it to test their proposition.
}

\subsubsection{Citation types}

One of the authors trained a team of graduate students to code citation types. These students had high grades and high motivation towards academic research. We first described the citation types in detail to the research assistants (RAs) and provided examples of each citation type. Then, each RA and one of the authors coded a set of 515 citations to 10 articles in our sample. The mean ICC (Intra-Class Correlation) over all the citation types was equal to .78, which is satisfactory (Shrout \& Fleiss, 1979).

Next, the RAs classified each citing manuscript into one of the five types of citation. In case a citing manuscript used several types of citation, they retained the type of citation that most strongly signaled a contribution to the evolution of science. As argued above, based on prior literature, application, affirmation and negation citation are the strongest types of citation and do not co-occur, given their definitions. Review citations are typically less indicative of scientific merit than the former types, but they are more indicative of scientific merit than perfunctory mentions (Baumgartner \& Pieters, 2003; Hanney et al., 2005; Moravcsik \& Murugesan, 1975; Small, 2004).

From the total of 29,320 citing papers to the 659 cited articles in our sample, our RAs were able to code the citation types for 24,632 citing papers. Thus, they could not code the citation type for 4,688 citing papers for two reasons. First, some of the citing articles are from sources for which neither of our schools holds a valid subscription. ${ }^{5}$ In such cases, we could only retrieve an abstract or extended abstract, which is not enough to code citation types. Second, some citing articles are published in a language other than English and hence, we could not reliably code them in terms of citation types. Two of the authors examined these missing citations and did not find any particular pattern besides the fact that these missing references are often from lower tier journals and/or fields outside marketing. We also examined the 10 articles with the highest number of missing citations. In $95 \%$ of all cases, the citing paper was missing because we did not have access to its full text. In $5 \%$ of all cases, the citing paper was not written in English.

\subsubsection{Determinants of citation behavior}

Stremersch et al. (2007) introduced a comprehensive framework which organizes the determinants of citation behavior according to three perspectives: universalism ("what" the authors say), social constructivism ("who" the authors are) and presentation ("how" the authors say what they say). Therefore we adopt the same measures as Stremersch et al. (2007) to operationalize these three perspectives. We also extend this framework to include the degree to which a paper challenges commonly held beliefs.

We also develop a measurement instrument containing 8 reflective items, based on Davis (1971) to measure the degree to which a paper challenges commonly held beliefs. We used seven-point Likert scales to indicate the level of agreement of the coder with the included statements ( 1 = "completely disagree", and $7=$ "completely agree"). Afterwards, one of the authors and the team of RAs used this scale to contentcode all 659 articles in our sample on the extent to which they challenge commonly held beliefs. In the Appendix, we provide a detailed overview of the approach and scale we used to measure Challenging Commonly Held Beliefs $\left(\mathrm{CCHB}_{i j}\right)$, i.e. the extent to which an article $i$ published in journal $j$ challenges commonly held beliefs of its audience. Given the ordinal nature of the response scale we used to measure challenging commonly held beliefs, we computed $C C H B_{i j}$ directly from the median score, across the eight items of our scale and across coders, following

\footnotetext{
${ }^{5}$ Note that for each article published in an ISI journal, Thomson Reuters counts all article citations in peer-reviewed sources, even those in non-ISI peer reviewed journals and those in peer reviewed conference proceedings.
} 
Table 1

Measurement of variables.

\begin{tabular}{|c|c|}
\hline Variable & Measurement \\
\hline \multicolumn{2}{|c|}{ Dependent variables } \\
\hline Citation & The number of articles across all journals in the ISI-SSCI that cite the article until end of December 2009 \\
\hline Citation types & $\begin{array}{l}\text { The number of articles across all journals in the ISI-SSCI that cite the article until the end of December 2009, according to one of the } \\
\text { following types of citation: (1) application, (2) affirmation, (3) negation, (4) review and (5) perfunctory mention. In case a citing } \\
\text { manuscript used several types of citation, we retained the type of citation that most strongly signaled a contribution to the evolution } \\
\text { of science. Application, affirmation and negation citation are the strongest types of citation and do not co-occur, given their definitions. } \\
\text { Review citations are typically less indicative of scientific merit than the former types, but they are more indicative of scientific merit } \\
\text { than perfunctory mentions. }\end{array}$ \\
\hline
\end{tabular}

Universalist perspective: challenging commonly held beliefs

Challenging commonly held The level of challenging commonly held beliefs intended by the focal article, according to the median score of the article across raters beliefs and across the 8 items in our disconfirming commonly held beliefs scale (see Appendix)

Universalist perspective: quality

Article order $[R]$

Awards

Article length

Universalist perspective: domain Orientation

Method type

Subject area
Ordinal variable from 1 to $\mathrm{n}$, representing the order in which the article was listed in the issue

Dummy equal to 1, if the article won any of the following awards, best-article awards at JCR and IJRM, the Harold H. Maynard Award and the MSI/H. Paul Root Award at JM, the Paul E. Green Award and the William F. O'Dell Award at JMR, and the J.D.C. Little Award at MKS, 0, otherwise

Count variable of the number of pages of the article

Two dummies: behavioral and quantitative, equal to 1 if article belongs to orientation, 0 otherwise. An article may cover multiple orientations. Note that managerial orientation has been reported as highly collinear with behavioral (Stremersch et al., 2007). Therefore we do not retain it as a separate category.

Four dummies: conceptual, empirical, methodological, and analytical, equal to 1 if article belongs to method type, 0 otherwise. An article may cover multiple method types.

19 dummy variables indicating whether the article belongs to a subject area, equal to 1 if article belongs to a subject area, 0 otherwise. An article may cover multiple subject areas.

Social constructivist perspective: visibility

Publication record The number of publications in the five journals we consider of all authors of the article before the article appeared

Editorial board membership Dummy equal to 1 if at least one of the authors of an article has been a member of the editorial board of IJRM, JCR, JM, JMR, or MKS, between the year of publication of the article and two years after publication, 0 otherwise.

Business school ranking [R] The average business school ranking across all authors of an article (based on the business school ranking of Financial Times in 2009)

Centrality [R]

The minimum individual centrality across the authors of the article from Goldenberg et al. (2010)

U.S. affiliation

Share of the authors of the article having a U.S. affiliation

Nr. of authors

Count of the number of authors of the article

Social constructivist perspective: personal promotion

Reference intensity The number of references in the reference list of the article

Self-citation intensity The number of self-citations by all authors of the article until December 31, 2009

Presentation perspective: title length

Title length The number of significant words in the title of article

Presentation perspective: attention grabbers

"Marketing" in title Dummy, equal to 1 if the word "marketing" is in the title of the article, 0 otherwise.

"Market" in title Dummy, equal to 1 if the word "market" is in the title of the article, 0 otherwise.

"New" in title Dummy, equal to 1 if the word "new" is in the title of the article, 0 otherwise.

Nr. keywords

Count of the number of keywords as assigned by ISI

Presentation perspective: expositional clarity

Nr. equations Count of the number of equations in the article

Nr. figures Count of the number of figures in the article

$\mathrm{Nr}$. tables Count of the number of tables in the article

$\mathrm{Nr}$. footnotes Count of the number of footnotes in the article

Nr. appendices Count of the number of appendices in the article

Reading ease

The Flesch reading ease score. Articles with a higher score are easier to understand.

the arguments in marketing research textbooks such as Aaker, Kumar, and Day (2004) and Malhotra, Birks, and Wills (2010).

We summarize the measurement of all variables in Table 1 below and provide basic descriptives in Table 2.

\subsection{Descriptives}

The last three rows of Table 3 (in bold) contain the frequency and average number of citations of each type across all journals. The majority were review citations (13,025; 52.9\%). Perfunctory mentions also frequently occur (7830; 31.8\%). Application citations (2500; 10.1\%) and affirmation citations $(1128 ; 4.6 \%)$ are less frequent. Negation citations are rare $(149 ; 0.6 \%)$. In other words, only approximately $15 \%$ of all citations show irrefutable scientific merit from citing to cited article. ${ }^{6}$ This finding supports citation type as an important measure to complement a mere count of citations.

While we find a high percentage of perfunctory mentions (31.8\%), similar frequencies of perfunctory citations have been found in other fields. For instance, Krampen, Becker, Wahner, and Montada (2007) examine 3,528 citations to 90 journal articles in five psychology journals and find that perfunctory mentions account for about $25 \%$ of citations.

\footnotetext{
${ }^{6}$ Interestingly, among the $15 \%$ of citations that signal irrefutable scientific merit from citing to cited article, the largest share belongs to application citations. This result suggests that marketing scholars tend to recognize scientific indebtedness by building on each other's work and on concepts proposed by prior literature. We thank an anonymous reviewer for raising this issue.
} 
Table 2

Data descriptives.

\begin{tabular}{|c|c|c|c|}
\hline & Variable & Value & Entire sample \\
\hline \multirow[t]{6}{*}{ Dependent variables } & Citations & Average [range] & $44.49[0,662]$ \\
\hline & Citation functions: Application & Average [range] & $3.79[0 ; 194]$ \\
\hline & Citation functions: Affirmation & Average [range] & $1.71[0 ; 37]$ \\
\hline & Citation functions: Negation & Average [range] & $.23[0 ; 4]$ \\
\hline & Citation functions: Review & Average [range] & $19.76[0 ; 290]$ \\
\hline & Citation functions: Perfunctory & Average [range] & $11.88[0 ; 197]$ \\
\hline \multirow[t]{29}{*}{ Universalist perspective } & Challenging commonly held beliefs $\left(\mathrm{CCHB}_{\mathrm{ij}}\right)$ & Average [range] & $3.00[1 ; 6]$ \\
\hline & Quality: Article order [R] & Average [range] & $5.18[1,18]$ \\
\hline & Quality: Awards & Average [range] & $0.03[0,1]$ \\
\hline & Quality: Article length & Average [range] & $14.72[4,35]$ \\
\hline & Domain-Orientation: Behavioral & Count & 412 \\
\hline & Domain-Orientation: Quantitative & Count & 195 \\
\hline & Domain-Method type: Conceptual & Count & 274 \\
\hline & Domain-Method type: Empirical & Count & 534 \\
\hline & Domain-Method type: Methodological & Count & 113 \\
\hline & Domain-Method type: Analytical & Count & 115 \\
\hline & Domain-Subject area: New products & Count & 49 \\
\hline & Domain-Subject area: B2B & Count & 68 \\
\hline & Domain-Subject area: Relationship marketing & Count & 39 \\
\hline & Domain-Subject area: Brand \& product management & Count & 105 \\
\hline & Domain-Subject area: Advertising & Count & 81 \\
\hline & Domain-Subject area: Pricing & Count & 61 \\
\hline & Domain-Subject area: Promotions & Count & 33 \\
\hline & Domain-Subject area: Retailing & Count & 41 \\
\hline & Domain-Subject area: Strategy & Count & 114 \\
\hline & Domain-Subject area: Sales & Count & 41 \\
\hline & Domain-Subject area: Methodology & Count & 75 \\
\hline & Domain-Subject area: Services & Count & 30 \\
\hline & Domain-Subject area: Consumer knowledge & Count & 79 \\
\hline & Domain-Subject area: Consumer emotions & Count & 49 \\
\hline & Domain-Subject area: Other consumer behavior & Count & 64 \\
\hline & Domain-Subject area: Consumption behavior & Count & 41 \\
\hline & Domain-Subject area: International marketing & Count & 25 \\
\hline & Domain-Subject area: Other & Count & 35 \\
\hline & Domain-Subject area: E-commerce & Count & 19 \\
\hline \multirow[t]{8}{*}{ Social constructivist perspective } & Visibility: Publication record & Average [range] & $11.11[0,65]$ \\
\hline & Visibility: Editorial board membership & Average [range] & $0.64[0,1]$ \\
\hline & Visibility: Business school ranking [R] & Average [range] & $60.42[1,101]$ \\
\hline & Visibility: Centrality $[\mathrm{R}]$ & Average [range] & $5.97[4.49,10.88]$ \\
\hline & Visibility: U.S. affiliation & Average [range] & $0.79[0,1]$ \\
\hline & Visibility: Number of authors & Average [range] & $2.31[1,6]$ \\
\hline & Personal promotion: Reference intensity & Average [range] & $47.01[0,315]$ \\
\hline & Personal promotion: Self-citation intensity & Average [range] & $2.42[0,33]$ \\
\hline \multirow[t]{11}{*}{ Presentation perspective } & Title length & Average [range] & $7.41[1,16]$ \\
\hline & Attention grabbers: "Marketing" in the title & Count & 60 \\
\hline & Attention grabbers: "Market" in the title & Count & 61 \\
\hline & Attention grabbers: "New" in the title & Count & 42 \\
\hline & Attention grabbers: Number of keywords & Average [range] & $6.63[1,11]$ \\
\hline & Expositional clarity: Number of equations & Average [range] & $4.18[0,34]$ \\
\hline & Expositional clarity: Number of figures & Average [range] & $1.93[0,16]$ \\
\hline & Expositional clarity: Number tables & Average [range] & $3.55[0,29]$ \\
\hline & Expositional clarity: Number of footnotes & Average [range] & $5.95[0,38]$ \\
\hline & Expositional clarity: Number of appendices & Average [range] & $0.63[0,13]$ \\
\hline & Expositional clarity: Reading ease & Average [range] & $35.22[12.89,64.99]$ \\
\hline \multirow[t]{5}{*}{ Journal dummies } & JCR & Count & 141 \\
\hline & $\mathrm{JM}$ & Count & 144 \\
\hline & JMR & Count & 143 \\
\hline & IJRM & Count & 88 \\
\hline & MKS & Count & 143 \\
\hline
\end{tabular}

These authors also mention that the proportions of perfunctory mentions in other fields, namely Physics, Sociology and Demography, are even higher (up to $40 \%$ of all citations). Moravcsik and Murugesan (1975) analyzed 2,286 references in 30 articles in Physical Review published between 1968 and 1972 and found that perfunctory mentions represented $41 \%$ of all citations.

Cano (1989) asked 21 engineering scholars to classify their citations, in two of their recent papers, according to citation type and to indicate the degree to which a citation was indispensable for their paper. Scholars classified $25.8 \%$ of their own citations as perfunctory, and they admitted that such citations had the lowest 'utility' level. The only exception to these high proportions of perfunctory citations comes from a study by Peritz (1983) who found only $3.7 \%$ of perfunctory mentions among the citations to 106 articles published in five journals in different fields. ${ }^{7}$

The results we obtain for the marketing journals we study suggest a high frequency of perfunctory mentions, which may make inference on impact based solely on number of citation counts problematic. Mere

7 Am. J. Sociology ( $N=16$ in 1977/80), Am. J. Epidemiology ( $N=22$ in 1980), Library Res. $(\mathrm{N}=12$ in 1980), Am. J. Educ. Res. $(\mathrm{N}=27$ in 1980) and Demography ( $=29$ in 1978). 
Table 3

Frequency of citation types.

\begin{tabular}{|c|c|c|c|c|c|c|}
\hline Journal & Application & Affirmation & Negation & Review & Perfunctory & Total freq. \\
\hline IJRM & 85 & 50 & 10 & 574 & 274 & 993 \\
\hline \% within IJRM & $8.6 \%$ & $5.0 \%$ & $1.0 \%$ & $57.8 \%$ & $27.6 \%$ & \\
\hline JCR & 549 & 255 & 24 & 2,712 & 1,666 & 5,206 \\
\hline \% within JCR & $10.5 \%$ & $4.9 \%$ & $0.5 \%$ & $52.1 \%$ & $32.0 \%$ & \\
\hline JM & 921 & 344 & 41 & 4,778 & 2,782 & 8,866 \\
\hline \% within JM & $10.4 \%$ & $3.9 \%$ & $0.5 \%$ & $53.9 \%$ & $31.4 \%$ & \\
\hline JMR & 668 & 270 & 41 & 2,748 & 1,634 & 5,361 \\
\hline$\%$ within JMR & $12.5 \%$ & $5.0 \%$ & $0.8 \%$ & $51.3 \%$ & $30.5 \%$ & \\
\hline MKS & 277 & 209 & 33 & 2,213 & 1,474 & 4,206 \\
\hline$\%$ within MKS & $6.6 \%$ & $5.0 \%$ & $0.8 \%$ & $52.6 \%$ & $35.0 \%$ & \\
\hline Total frequency & 2,500 & 1,128 & 149 & 13,025 & 7,830 & 24,632 \\
\hline$\%$ of total & $10.1 \%$ & $4.6 \%$ & $0.6 \%$ & $52.9 \%$ & $31.8 \%$ & \\
\hline Avg. citations & 3.8 & 1.7 & 0.2 & 19.8 & 11.9 & $37.4^{\mathrm{a}}$ \\
\hline
\end{tabular}

a We computed this value from the total number of citations, across all types, which we were able to retrieve for the 659 cited articles in our sample (24,632). Had we used the total number of citations including those for which citation type is missing $(29,320)$, we would obtain a higher value (44.5).

citation counts may not necessarily represent the true scholarly impact of an article or author, if perfunctory mentions are a large share of such citation counts.

Next, we compare the respective journals in our sample (see Table 3). The relative frequency of perfunctory citations to articles in IJRM was significantly lower (27.6\%), as compared to articles in other journals. Pairwise z-tests show that these differences were statistically significant, at the $5 \%$ level, for JCR (which had $32.0 \%$ of perfunctory cites, $p<.01)$, JM (31.4\%, $p=.014)$ and MKS $(35.0 \%, p<.01)$ and, at the $10 \%$ level, for JMR $(30.5 \%, p=.07)$. For articles in MKS the relative frequency of perfunctory citations was higher $(35.0 \%)$ than all other journals, with these differences statistically significant at the $1 \%$ level. The relative frequency of review citations to IJRM articles (57.8\%) was significantly higher, than to articles in all other journals (with all $p$-values smaller than .01 except for JM, where $p=.02$ ). The relative frequency of review citations to JM articles (53.9\%) was statistically significantly higher (at the $5 \%$ level) than to articles in JCR $(52.1 \% ; p=.04)$ and JMR (51.3\%; $p<.01)$, but not in MKS (52.6\%; $p=.17)$. The differences between JMR and MKS ( $p=.19)$, JCR and MKS ( $p=.61)$, and JMR and JCR ( $p=.39)$ were statistically insignificant.

The relative frequency of negation citations to articles in JCR (0.5\%) and JM (0.5\%) was statistically significantly lower (at the $5 \%$ level) than to articles in IJRM ( $1.0 \% ; p=.03$ for JCR and $p=.02$ for JM), JMR $(0.8 \% ; p=.05$ for JCR and $p=.02$ for JM) and MKS $(0.8 \% ; p=.04$ for JCR and $p=.02$ for JM). There were no statistically significant differences between JCR and JM ( $p=.99)$ or among IJRM and JMR $(p=.43)$, IJRM and MKS ( $p=.49)$, and JMR and MKS $(p=.91)$. The relative frequency of affirmation citations to articles in JM (3.9\%) was statistically significantly lower than to articles in all other journals (with $p$-values smaller than .01 for JCR, JMR and MKS and $p=.08$ for IJRM). The relative frequency of application citations to articles in JMR (12.5\%) was statistically significantly higher, than to articles in the other journals (with all differences statistically significant at the $1 \%$ level). The relative frequency of application citations to articles in MKS (6.6\%) was lower than to articles in the other journals (all differences significant at the $1 \%$ level except IJRM with $p=.03$ ).

\section{Model and results}

\subsection{Model specification}

We specify the following model:

$$
\begin{aligned}
\text { CITE }_{i j}= & \alpha+\varphi_{1} * \operatorname{CCHB}_{i j}+\varphi_{2} * \operatorname{CCHB}_{i j}^{2}+\sum_{j=1}^{4}\left(\beta_{j} * D_{j}\right) \\
& +\sum_{j=1}^{5} \chi_{j} Q_{i j}+\sum_{j=1}^{5} \delta_{j} Q_{i j}^{2}+\sum_{u=1}^{U} \gamma_{u} * x_{u i j}+\sum_{s=1}^{S} \eta_{s} * x_{s i j}+\sum_{p=1}^{P} \iota_{p} * x_{p i j}+\varepsilon_{i j}
\end{aligned}
$$

where $C_{I T E_{i j}}$ is the number of citations an article $i$ in journal $j$ has received. $\alpha$ is the model intercept and $C_{C H B}$ is the extent to which article $i$ in journal $j$ challenges commonly held beliefs. We include a linear and a quadratic term to capture non-linear effects of challenging commonly held beliefs on citations. $D_{j}$ represents journal dummies for IJRM, JCR, JM and JMR (MKS serves as the baseline). $Q_{i j}$ (number of quarters since the article appeared) and its squared term $Q_{i j}{ }^{2}$ correct for the time the article has been out, which we estimate as journal-specific. The $x$-vectors represent the remaining universalist determinants of citations (i.e. beyond challenging commonly held beliefs; $x_{u i j}, u=1, \ldots, 28$ ), the social constructivist determinants of citations $\left(x_{s i j}, s=1, \ldots, 8\right)$, and the presentation determinants of citations $\left(x_{p i j}, p=1, \ldots, 11\right)$ of article $i$ in journal $j$.

We also estimate the model in Eq. (1) for each of the five types of citation, i.e. (1) APPLICATION $i j$, (2) AFFIRMATION $i j$, (3) NEGATION (4) REVIEW $i j$ and (5) PERFUNCTORY $Y_{i j}$.

The standard model for the analysis of count data, such as citation counts, is the Poisson regression model. Poisson regression, however, constrains the (estimated) variance of the data to be equal to the (estimated) mean, conditional on the explanatory variables, an assumption that is often violated (Cameron \& Trivedi, 1990). When the meanvariance equality assumption is violated, the observed variance of the dependent variable is typically higher than the variance estimated using the Poisson model, a problem known as overdispersion and whose consequences are similar to those of heteroscedasticity in the linear regression model (consistent parameter estimates but inconsistent standard errors leading to invalid hypothesis testing; Cameron \& Trivedi, 1990). The procedure developed by Cameron and Trivedi (1990) shows that this is the case in our models: there is substantial overdispersion in all models (citations and citation types). Thus, we estimate negative binomial models, use a quasi-maximum likelihood procedure and a quadratic hill-climbing optimization algorithm and apply Cameron and Trivedi's (1990) correction for overdispersion. If the conditional mean is correctly specified, quasi-maximum likelihood estimators are robust and produce consistent estimates and standard errors of the parameters of interest.

\subsection{Model fit}

We use the Likelihood Ratio Index (LRI) and AIC (Akaike Information Criterion) to compare the fit of the full model with a null model. The null model contains an intercept, journal dummies and the number of quarters the article has been out (including its squared value). The LRI of our full model compared to this null model is .13, which represents a satisfactory fit. Note that the LRI takes more conservative values than the R-squared fit measure, used in OLS regression. The AIC of our full model is 8.77 , while the AIC of the null model is 9.90, which 
Table 4

Estimation results. ${ }^{\text {a }}$

\begin{tabular}{|c|c|c|c|c|c|c|c|}
\hline & & M1 - Citations & M2 - Application & M3 - Affirmation & M4 - Negation & M5 - Review & M6 - Perfunctory \\
\hline \multirow{31}{*}{$\begin{array}{l}\text { Universalist } \\
\text { perspective }\end{array}$} & Intercept & $1.14^{* *}$ & -.39 & $-2.90^{* * *}$ & -2.74 & .14 & -.51 \\
\hline & Challenging commonly held beliefs & $.23^{* *}$ & .22 & $.42^{* *}$ & -.46 & $.28^{* * *}$ & $.43^{* * *}$ \\
\hline & (Challenging commonly held beliefs) $^{2}$ & $-.03^{* *}$ & -.03 & $-.06^{* *}$ & .09 & $-.03^{* *}$ & $-.07^{* * *}$ \\
\hline & Quality: article order [R] & $.02 * 10^{-2}$ & $-.26 * 10^{-2}$ & $1.78 * 10^{-2}$ & $.18 * 10^{-2}$ & $.54 * 10^{-2}$ & $-.73 * 10^{-2}$ \\
\hline & Quality: awards & $.35^{* * *}$ & $.49^{* * * *}$ & $.45^{* *}$ & $.67^{*}$ & $.37^{* * *}$ & $.47^{* * *}$ \\
\hline & Quality: article length & $.03^{* * *}$ & $.04^{* * *}$ & -.02 & .06 & $.02^{* * *}$ & $.04^{* * *}$ \\
\hline & Domain-orientation: behavioral & .01 & $-.20^{* *}$ & .04 & -.33 & -.03 & $.16^{* *}$ \\
\hline & Domain-orientation: quantitative & -.02 & $-.25^{*}$ & -.05 & -.47 & .03 & -.01 \\
\hline & Domain-method type: conceptual & $.17^{* * *}$ & $.21^{* *}$ & $.23^{* *}$ & .07 & $.11^{* *}$ & $.31^{* * *}$ \\
\hline & Domain-method type: empirical & $.14^{*}$ & $.48^{* * *}$ & $.28^{* *}$ & .24 & .01 & $.28^{* * *}$ \\
\hline & Domain-method type: methodology & $-.24^{* * *}$ & .16 & -.28 & .16 & $-.33^{* * *}$ & -.18 \\
\hline & Domain-method type: analytical & -.14 & -.25 & -.11 & .19 & $-.29^{* * *}$ & .19 \\
\hline & Domain-subject area: new products & .05 & $-.52^{* * *}$ & .06 & -.36 & .03 & $.28^{* *}$ \\
\hline & Domain-subject area: B2B & $.16^{*}$ & $.40^{* * *}$ & $.34^{* *}$ & .28 & .08 & $.27^{* *}$ \\
\hline & Domain-subject area: relationship marketing & $.74^{* * *}$ & $.74^{* * *}$ & $.77^{* * *}$ & .21 & $.67^{* * *}$ & $.81^{* * *}$ \\
\hline & Domain-subject area: brand \& prod. management & $.23^{* * *}$ & .12 & .09 & $.56^{* *}$ & $.23^{* * *}$ & $.30^{* * *}$ \\
\hline & Domain-subject area: advertising & $-.14^{*}$ & $-.44^{* * *}$ & .20 & .42 & $-.14^{*}$ & $-.27^{* * *}$ \\
\hline & Domain-subject area: pricing & -.07 & $-.52^{* * *}$ & .00 & -.05 & -.10 & $.18^{*}$ \\
\hline & Domain-subject area: promotions & $-.24^{* *}$ & -.23 & .04 & .40 & -.19 & $-.25^{*}$ \\
\hline & Domain-subject area: retailing & $.22^{* *}$ & -.14 & .16 & -.20 & $.21^{* *}$ & $.20^{*}$ \\
\hline & Domain-subject area: strategy & .11 & $.25^{* *}$ & $.42^{* * *}$ & .25 & $.20^{* *}$ & $-.19^{* *}$ \\
\hline & Domain-subject area: Sales & -.10 & .14 & .01 & .13 & -.07 & -.04 \\
\hline & Domain-subject area: methodology & .09 & $.25^{*}$ & .11 & -.32 & .04 & -.01 \\
\hline & Domain-subject area: services & $.43^{* * *}$ & $.70^{* * *}$ & $.74^{* * *}$ & $.81^{* *}$ & $.51^{* * *}$ & .16 \\
\hline & Domain-subject area: consumer knowledge & -.11 & $-.45^{* * *}$ & .11 & -.53 & -.01 & $-.33^{* * *}$ \\
\hline & Domain-subject area: consumer emotions & -.01 & $.30^{* *}$ & .04 & -.25 & .01 & .06 \\
\hline & Domain-subject area: other consumer behavior & $.16^{*}$ & .15 & -.04 & -.27 & $.15^{*}$ & .18 \\
\hline & Domain-subject area: consumption behavior & .12 & .12 & .18 & .58 & .06 & $.26^{* *}$ \\
\hline & Domain-subject area: international marketing & .07 & $.43^{* *}$ & .00 & .16 & .11 & -.02 \\
\hline & Domain-subject area: other & -.05 & $-.55^{* *}$ & -.19 & -.57 & .12 & $-.36^{* * *}$ \\
\hline & Domain-subject area: e-commerce & $.94^{* * *}$ & $.87^{* * *}$ & $.70^{* * *}$ & $.94^{* *}$ & $1.07^{* * *}$ & $.85^{* * *}$ \\
\hline \multirow{8}{*}{$\begin{array}{l}\text { Social } \\
\text { constructivist } \\
\text { perspective }\end{array}$} & Visibility: publication record & $.73 * 10^{-2 * * *}$ & $1.41 * 10^{-2 * * *}$ & $1.47 * 10^{-2 * * *}$ & $1.89 * 10^{-2 * *}$ & $.87 * 10^{-2 * * *}$ & $.59 * 10^{-2 *}$ \\
\hline & Visibility: editorial board membership & .07 & .07 & .11 & .37 & .01 & $.19^{* * * *}$ \\
\hline & Visibility: business school ranking [R] & $-.19 * 10^{-2 * *}$ & $.07 * 10^{-2}$ & $-.32 * 10^{-2 * *}$ & $-.21 * 10^{-2}$ & $-.17 * 10^{-2^{* *}}$ & $-.27 * 10^{-2 * * *}$ \\
\hline & Visibility: centrality [R] & -.03 & -.01 & .03 & .15 & -.01 & .01 \\
\hline & Visibility: U.S. affiliation & -.03 & .05 & .09 & .22 & .05 & -.09 \\
\hline & Visibility: number of authors & -.03 & $.10^{*}$ & .07 & -.06 & -.04 & -.04 \\
\hline & Pers. promotion: reference intensity & $.24 * 10^{-2 *}$ & $-.59 * 10^{-2 * * *}$ & $32 * 10^{-2}$ & $-.68 * 10^{-2}$ & $.20 * 10^{-2}$ & $.31 * 10^{-2^{* *}}$ \\
\hline & Pers. promotion: self-citation intensity & $.10^{* * *}$ & $.10^{* * *}$ & $.11^{* * * *}$ & $.09^{* * *}$ & $.09^{* * *}$ & $.10^{* * *}$ \\
\hline \multirow{11}{*}{$\begin{array}{l}\text { Presentation } \\
\text { perspective }\end{array}$} & Title length & $-.02^{* *}$ & $-.09^{* * *}$ & $-.04^{* *}$ & .01 & $-.03^{* * *}$ & .00 \\
\hline & Att. grabbers: 'Marketing' in title & .00 & -.19 & $-.30^{*}$ & -.40 & .03 & -.03 \\
\hline & Att. grabbers: 'Market' in title & -.04 & $-.24^{*}$ & -.16 & -.19 & $-.18^{* *}$ & $.19^{*}$ \\
\hline & Att. grabbers: 'New' in title & .08 & $.61^{* * *}$ & -.31 & -.08 & $.18^{*}$ & -.08 \\
\hline & Att. grabbers: nr. keywords & $-1.25 * 10^{-2}$ & $1.96 * 10^{-2}$ & $1.37 * 10^{-2}$ & $-.28 * 10^{-2}$ & $.30 * 10^{-2}$ & $-4.14 * 10^{-2 * * *}$ \\
\hline & Expositional clarity: nr. equations & $.02 * 10^{-2}$ & $-.38 * 10^{-2}$ & $1.07 * 10^{-2}$ & $.90 * 10^{-2}$ & $.15 * 10^{-2}$ & $-.38 * 10^{-2}$ \\
\hline & Expositional clarity: nr. figures & $-.42 * 10^{-2}$ & $-.37 * 10^{-2}$ & $.44 * 10^{-2}$ & $1.14 * 10^{-2}$ & $-.00 * 10^{-2}$ & $-2.50 * 10^{-2 *}$ \\
\hline & Expositional clarity: nr. tables & $-1.26 * 10^{-2}$ & $.72 * 10^{-2}$ & $2.19 * 10^{-2}$ & $-2.56 * 10^{-2}$ & $-.18 * 10^{-2}$ & $-3.81 * 10^{-2 * * *}$ \\
\hline & Expositional clarity: nr. footnotes & $.71 * 10^{-2}$ & $-.07 * 10^{-2}$ & $1.69 * 10^{-2 *}$ & $-.53 * 10^{-2}$ & $1.17 * 10^{-2^{* *}}$ & $-.57 * 10^{-2}$ \\
\hline & Expositional clarity: nr. appendices & $5.27 * 10^{-2^{* *}}$ & $8.76 * 10^{-2^{* *}}$ & $7.93 * 10^{-2^{* *}}$ & $-7.93 * 10^{-2}$ & $5.42 * 10^{-2^{* *}}$ & $1.41 * 10^{-2}$ \\
\hline & Expositional clarity: reading ease & $-.02^{* * *}$ & $-.04^{* * *}$ & $-.03^{* * *}$ & $-.06^{* * *}$ & $-.02^{* * *}$ & $-.01^{* * *}$ \\
\hline
\end{tabular}

$* p<.10 ; * * p<.05 ; * * * p<.01$ (two-sided tests).

a In all models we included journal dummies and time controls (number of quarters since publication and its square). We do not report these results here for parsimony, but the results are available upon simple request.

indicates that our full model fits better. The same fit statistics for the citation type models are also satisfactory.

\subsection{Determinants of citation counts}

We present our model estimates in Table $4 .{ }^{8}$ Column 3 contains the parameter estimates of the total citations model, and thus captures the determinants of citation counts. We find an inverted-U relationship between the degree of challenging commonly held beliefs and citations. Articles that challenge commonly held beliefs may be more influential $\left(\varphi_{1}=.23, p<0.05\right)$, as measured by citations, but this does not apply

\footnotetext{
${ }^{8}$ We only discuss significant results in the body of the text for brevity.
}

to articles that challenge commonly held beliefs to a very high degree, as we find a negative quadratic effect $\left(\varphi_{2}=-.03 ; p<.05\right){ }^{9}$

In the top left block of Fig. 1 we depict the effect of challenging commonly held beliefs on total citation counts. The X-axis presents the degree to which an article challenges commonly held beliefs. The Y-axis presents the expected number of citations, at each level of challenging commonly held beliefs, all else constant. We obtained the expected number of citations using the estimated parameters as follows. We kept all remaining variables at their sample mean and

\footnotetext{
${ }^{9}$ Interestingly, prior work in the new product development literature shows that moderately new products are more widely accepted and successful than incrementally new products and really new products (Goldenberg, Lehmann, \& Mazursky, 2001). Goldenberg et al. (2001) offer as a reason that new products are often perceived as offering too little advantage to consumers but really novel products are also perceived as being too complex.
} 
Avg. Nr. Citations

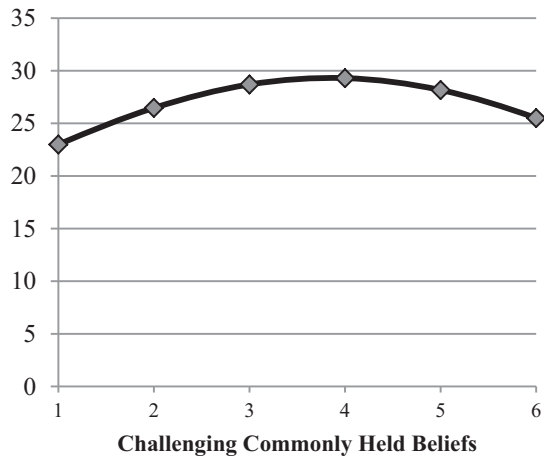

Avg. Nr. Review Citations

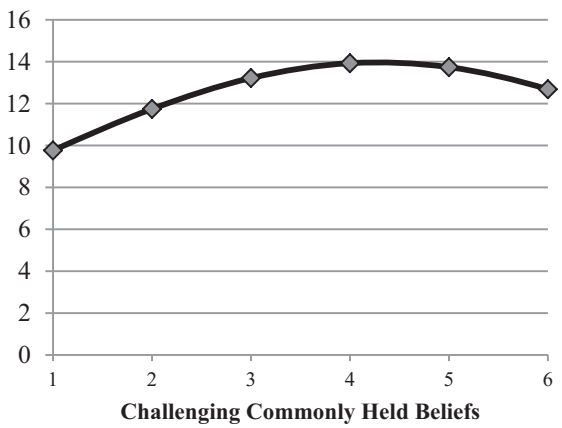

Avg. Nr. Affirmation Citations

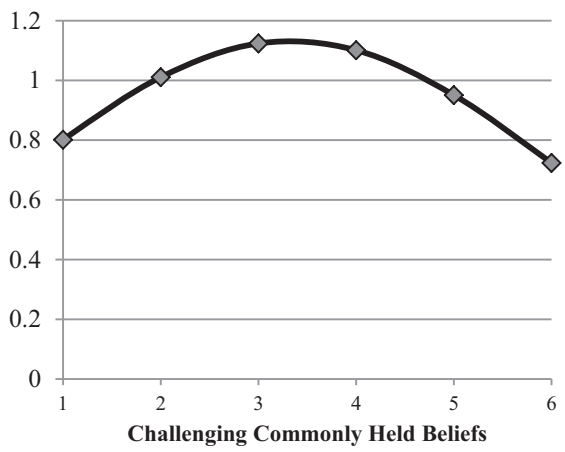

Avg. Nr. Perfunctory Citations

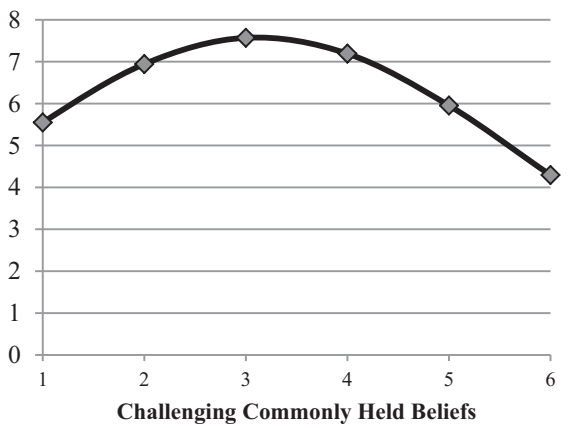

Fig. 1. Citations vs. challenging commonly held beliefs ${ }^{\mathrm{a}}$.

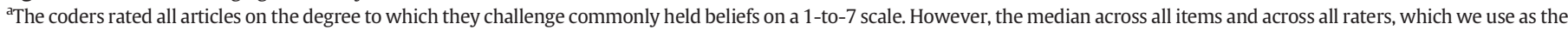

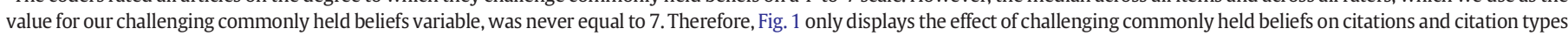
over a 1-to-6 range.

varied the degree to which a paper would challenge commonly held beliefs. Thus, Fig. 1 represents the number of citations that the average paper in our sample would receive at different levels of challenging commonly held beliefs.

From this graph, we can see that the highest expected number of citations occurs for a paper with a moderately high level of challenging commonly held beliefs (i.e. with $C C H B_{i j}=4$, on our 7-point scale). Such a paper (with $C C H B_{i j}=4$ ) receives, on average, 6.3 more citations than a paper with a low level of challenging commonly held beliefs (with $C C H B_{i j}=1$ ). From these 6.3 additional citations, approximately two thirds are review citations (4.2 additional review citations) and approximately one quarter are perfunctory mentions (1.6 additional perfunctory mentions).

Several other universalist determinants of citation counts show significant effects. Articles that receive journal awards $\left(\gamma_{2}=.35, p<.01\right)$ or are longer $\left(\gamma_{3}=.03, p<.01\right)$ also obtain more citations. Articles that use a conceptual method type $\left(\gamma_{6}=.17, p<.01\right)$ have more citations than other articles. Empirical articles also have more citations than other articles but the effect is only marginally significant $\left(\gamma_{7}=.14, p<.10\right)$. Articles that are methodological $\left(\gamma_{8}=-.24, p<.01\right)$ have fewer citations. We also find that some subject areas (e.g. business-to-business, relationship marketing and brand and product management) have more citations, on average, than other subject areas (e.g. advertising and promotions, see Table 4). These differences may be driven by variation in subject area popularity or in citation practices across subject areas.

When examining the social constructivist determinants, we find that articles from authors with an extensive publication record $\left(\eta_{1}=.73 * 10^{-2}, p<.01\right)$, or from highly ranked schools $\left(\eta_{3}=\right.$ $-.19 * 10^{-2}, p<.05$ [reverse-scored]) have more citations, consistent with the Matthew effect (Merton, 1968). Personal promotion, as operationalized by reference intensity $\left(\eta_{7}=.24 * 10^{-2}, p<.10\right)$ and selfcitation intensity $\left(\eta_{8}=.10, p<.01\right)$, positively affect the number of citations an article receives.

When examining the presentation determinants of citations, we find that title length $(\iota 1=-.02, p<.05)$ negatively affects the number of citations. The results for expositional clarity are mixed. We find that articles with more appendices $\left(\imath 10=5.27 * 10^{-2}, p<.05\right)$ have more citations than articles with fewer appendices. Articles that are easier to read $(\llcorner 11=-.02, p<.01)$ have fewer citations. The latter effect is consistent with Stremersch et al. (2007), who argued that more readable articles may be less credible to a scientific audience. Note that the positive effect of journal awards on citations and the negative effect of readability on citations do not imply that award-winning articles have lower readability. Sawyer et al. (2008), for instance, report that award-winning articles are more readable than non-winners. In our sample, the correlation between readability and award-winning is insignificantly different from zero $(\rho=.003$, n.s. $)$.

\subsection{Determinants of citation types}

The estimates of the citation type models are in columns 4-8 of Table 4. We find substantial contrast between citation types. Out of 49 determinants of citation types - including the linear and quadratic terms for challenging commonly held beliefs and excluding the intercept, journal dummies and time - only 13 effects have the same sign across all citation types. Of these 13 effects, only 5 are statistically significant across all citation types and 8 are statistically significant for some citation types, some at different significance levels, 
but statistically insignificant for other citation types. Wald tests confirm that, among the remaining 36 effects (i.e. among those which do not have the same sign across all citation types), 19 effects are significantly different across citation types at the $5 \%$ level. Three additional effects are significantly different at the $10 \%$ level. These results support the notion that a mere count of the number of citations may mask interesting contrasts in the motivations behind citing a paper. We mention some of the most striking results from the citation type analysis.

As we can see from Fig. 1, we find an inverted-U relationship between the degree of challenging commonly held beliefs and affirmation citations $\left(\varphi_{1}{ }^{A F F I R M}=.42, p<.05 ; \varphi_{2}{ }^{A F F I R M}=-.06, p<.05\right)$, review citations $\left(\varphi_{1}{ }^{R E V}=.28, p<.01 ; \varphi_{2}{ }^{R E V}=-.03, p<.05\right)$ and perfunctory citations $\left(\varphi_{1}{ }^{\text {PERF }}=.43, p<.01 ; \varphi_{2}{ }^{\text {PERF }}=-.07, p<.01\right)$.

We also find that articles of editorial board members receive more perfunctory cites than articles of scholars that are not editorial board members $\left(\eta_{2}{ }^{P E R F}=.19, p<.01\right)$, an effect we would not pick up in a model with only total number of citations as a dependent variable. Given that we control for many other variables, such as publication record, this effect suggests that authors may aim to please potential reviewers by citing their work or that editorial board members suggest authors to cite their own work in reviews they write. Even if only indirectly relevant, authors may accommodate such suggestions out of fear of being rejected.

A similar logic of "gaming citations" seems to apply to the number of references in a paper. The more references an article contains the more citations the article receives. However, we find that this effect is driven only by the effect of reference intensity on perfunctory mentions $\left(\eta_{7}{ }^{P E R F}=.31 * 10^{-2}, p<.05\right)$. The effect of reference intensity on application citations is negative $\left(\eta_{7}{ }^{A P L}=-.59 * 10^{-2}\right.$ $p<.01$ ). This may signal that reference intensity increases citation counts, not because of programmatic development of a research area, but more by a social constructivist logic, such as "you cite me, I cite you" behavior.

Another contrast across citation types is the significant and positive effect of the number of authors on the number of application cites $\left(\eta_{6}{ }^{A P L}=.10, p<.10\right)$, while this effect is not significant for other citation types nor the mere total count of citations. Articles written by more authors have more chance to be promoted, as authors are constrained both in time and network to do so. As the number of authors increases, the number of promotion opportunities increases as well (Stremersch et al., 2007). This may indeed particularly affect application cites, because they represent the direct usage of a concept, theory or technique by future work. Intense promotion of the article, at conferences, research camps, seminars, and the like, may stimulate such usage.

Finally, we find that title length negatively affects the number of application citations $\left(\iota_{1}^{A P P L}=-.09, p<.01\right)$, affirmation citations $\left(\iota_{1}{ }^{\text {AFFIRM }}=-.04, p<.05\right)$ and review citations $\left(\iota_{1}{ }^{R E V}=-.03, p<.01\right)$ but has no significant effect on the number of negation citations $\left(\iota_{1}{ }^{N E G}=.01, p=.88\right)$ or on the number of perfunctory mentions $\left(\iota_{1}\right.$ PERF $\left.=.00, p=.73\right)$.

\subsection{Robustness}

We conducted several robustness checks.

\subsubsection{Robustness: sampling}

To test for outliers, we computed the difference between the actual and predicted value for the dependent variable. Next, we excluded articles for which this difference did not lie within three standard deviations of the mean residual. This exclusion reduced the final sample size from 659 to 647 . The results are similar across all models.

In order to test whether the small sample size for negation cites ( $N=149)$ threatens the robustness of our results, we estimated three additional models for the negation equation: (i) a model with only challenging commonly held beliefs and the time and journal controls as independent variables (which means estimating only 17 parameters in this case), (ii) a model without domain variables (i.e. orientation, method type and subject area, for a total of 39 parameters) and (iii) a model with orientation and method but without subject area (45 parameters in total). We compared the results of these three models with our full model and found no meaningful differences, only some shifts in significance due to the reduced power in the full model.

We also tested the sensitivity of our results to age effects. Recently published articles may receive few citations in the first years since publication and introduce noise in our estimation. We tested whether restricting our sample to articles which had been published for at least 3,4 or 5 years, respectively, would change any of our results. We dropped all articles published in 2007 and re-estimated the model in the new smaller sample $(\mathrm{N}=619)$. We then repeated this procedure by also removing articles published in $2006(\mathrm{~N}=581)$ and in $2005(\mathrm{~N}=541)$. Our main results remained robust.

\subsubsection{Robustness: functional form}

We tested several alternative functional forms. First, we ran the same models using a series of dummies to discretize the level of challenging commonly held beliefs of the different papers, instead of assuming a curvilinear relationship between challenging commonly held beliefs and citations. We find similar results. Articles with a moderately high level of challenging commonly held beliefs receive more citations than articles with a low or very high level of challenging commonly held beliefs. Articles with a very high level of challenging commonly held beliefs receive more negation cites than other articles. The results from this analysis confirm the results from our models (as reported in Table 4). We tested whether treating challenging commonly held beliefs as a continuous variable (rather than using a series of dummy variables) leads to a loss of information (Long \& Reese, 2001) and it does not.

Second, we examined whether there are significant differences in the pattern of citations over time for papers with different levels of challenging commonly held beliefs. We specified a random effect negative binomial panel data model (Cameron \& Trivedi, 2014), with the number of citations that article $i$ in journal $j$ received in each year since its publication until 2009 as the dependent variable $\left(C_{T T E_{i j t}}\right)$ and, as independent variables, the number of years since publication (linear and quadratic, $t$ and $t^{2}$ ), our challenging commonly held beliefs variable (linear and quadratic, $\mathrm{CCHB}_{i j}$ and $\mathrm{CCHB}_{i j}{ }^{2}$ ) and interaction terms between the time and challenging commonly held beliefs variables $\left(t * C C H B_{i j}\right.$, $t * \mathrm{CCHB}_{i j}{ }^{2}$ and $\left.t^{2} * \mathrm{CCHB}_{i j}, t^{2} * \mathrm{CCHB}_{i j}{ }^{2}\right)$. The results again confirm an inverted-U relationship between challenging commonly held beliefs and citations. Even though this non-linear effect weakens over time (i.e. the effect of $C C H B_{i j}$ becomes less positive and the effect of $\mathrm{CCHB}_{i j}{ }^{2}$ becomes significantly less negative), articles with a low or very high level of challenging commonly held beliefs still receive fewer citations than articles with a moderately high level of challenging commonly held beliefs, even almost two decades after being published.

\subsubsection{Robustness: independent variables}

First, regarding our challenging commonly held beliefs variable, one may question how papers that identify boundary conditions or moderators are treated in our analyses. According to Davis (1971), contingency frameworks and moderating hypotheses increase the perception that a paper challenges commonly held beliefs. We empirically tested whether this is also validated by our measurement instrument. We trained a second set of RAs to 
indicate, for approximately $25 \%$ of our original sample of papers ( $\mathrm{N}=166)$, whether or not each paper tried to qualify prior beliefs by identifying boundary conditions and moderators ("contingency papers") or not ("non-contingency papers"). Through this procedure we identified 26 of such contingency papers. We indeed find that papers with contingency factors are coded by our original set of raters as moderately more disconfirmatory than papers without contingency factors. We also compared contingency and non-contingency papers in terms of citation counts and citation types. We did not find statistically significant differences for citation counts, nor for any of the citation types, possibly due to the small sample size.

Second, we explored a different approach for controlling for the age of an article. Instead of $Q_{i j}$ and $Q^{2}$, we included $Q_{i j}$ and $\ln \left(Q_{i j}\right)$. The results remain highly similar, with no sign reversals in significant parameters and rare changes in significance (e.g., in the time controls).

Third, we also ran all models with the independent variables standardized, which yielded similar results. The full results of the above analyses, which reinforce the robustness of our findings, are available from the authors upon simple request.

\section{Conclusion}

Different types of citation may signal different degrees of scientific merit and impact. Yet, content analyses of the citations papers receive are rare. We gathered empirical data on citation types on an unprecedented scale - 659 papers published between 1990 and 2007 in the top 5 marketing journals - and are the first to empirically examine the determinants of different citation types.

In our sample, $31.8 \%$ of all citations are perfunctory mentions and $52.9 \%$ are review citations. In other words, only $15 \%$ of all citations show irrefutable scientific merit from citing to cited article. Moreover, of 49 determinants of citation behavior, only 5 are statistically significant and have the same sign across citation types. Among the more noteworthy findings are the following. Editorial review board members receive more perfunctory citations than non-editorial board members, while for other types of citation they are cited equally frequently. Also articles with more references receive more perfunctory mentions, but not more citations of other types, confirming the "you cite me, I'll cite you" citation gaming, mentioned in prior literature.

In sum, these results suggest that inference on impact based solely on overall number of citation counts is problematic. Mere citation counts may not represent the true scholarly impact of an article or author. Moreover, perfunctory mentions may be inflated by the review and citation process. Such insights may lead scientific stakeholders to more carefully evaluate some of their practices.

First, journal editors could devote more attention to the frequent occurrence of cites that do not represent scientific merit from citing to cited article. Given our sample is composed of what are considered to be the top journals in marketing, this may even apply to a greater extent to other journals in marketing as well. Editors could raise awareness among reviewers and authors about perfunctory citation behaviors. At present, and derived from personal experience, most reviewers and editors devote little attention to reference lists and if attention is given, it is mostly focused on adding references that are seen as relevant or are their own, rather than on weeding out references with little scientific merit. Editors should also aim to assign reviewers based on criteria beyond the number of times the potential reviewer is cited in the paper.

At the same time, editors should develop procedures that make it harder for reviewers to force the authors to include their own work in the reference list. A policy that journals could easily implement would be to ask reviewers to indicate, in the review submission form, whether they have made a request to the authors to cite the reviewer's own work. Such policy would encourage the AE and the Editor to judge the appropriateness of the request, and possibly also reduce the number of occurrences. Some occurrences will be perfectly scholarly valid, but others will not.

Second, business schools and other evaluators of scholarly merit of professors should use citation metrics with great care. We showed a mere count of citations to be a relatively noisy metric. Moreover, we also showed (like scholars before us) that determinants such as article domain weigh in heavily on mere citation counts. This may be driven by variation in citation practices across domains. Variability in citation practices across disciplines, for instance, is a well-recognized problem which prevents direct comparability of citation counts across fields (Bornmann \& Daniel, 2008), unless appropriate corrective methods are applied (Radicchi et al., 2008). Therefore, administrators should refrain from cross-(sub)field comparisons on citations. Practices such as pushing faculty to topic areas with greater popularity and thus higher cites by default, regardless of the quality of the work, may be contested on the grounds of scholarly ethics.

We are convinced that it is better for business schools, if they use citation metrics to evaluate faculty, to use them as categorical measures, rather than as measures with interval-scale properties. Using an imperfect and noisy metric such as citation counts to directly rank and compare scholars implicitly assumes that citations can be treated as a continuous metric with interval-scale properties. Variability in citation practices and metric noise suggests that this assumption may be unwarranted. A categorical approach could include distributing faculty in three segments at most, such as the following: (1) non-influential scholars; (2) influential scholars; (3) truly exceptionally influential scholars. Administrators could choose different cut-offs, based on citation distributions inside the school, citation distributions in the field of study, or absolute counts of citations.

Given the inherent limitations in any usage of citations as a metric, administrators should also use other metrics to document impact of scholarly work. For example, for complex and important decisions (such as tenure and promotion decisions), administrators may develop a balanced scorecard of scientific impact that considers several dimensions of scholarly influence. These could include, but are not limited to: (1) major awards; (2) grant-writing ability; (3) impact on teaching practices; and (4) practice impact (as in Roberts, Kayande, \& Stremersch, 2014).

As a second contribution to scientometric research (in marketing), we demonstrated that articles that challenge commonly held beliefs are indeed, as hypothesized by Murray Davis, more influential, as measured by citations. However, this does not apply to articles that may have "gone too far" in challenging commonly held beliefs (which approximates the 98 percentile in the sample). We find that this inverted U-shaped effect of challenging commonly held beliefs on citations counts is statistically significant for three of the citation types: affirmation, review and perfunctory mention.

Given these findings, the present paper may be a relevant complement to the paper by Davis (1971) in doctoral education inside and outside marketing. It documents empirically that scientists who challenge the status quo gain from it through an increased impact, unless the challenge crosses a threshold that may lead the paper to be considered absurd. It is well-known that papers that challenge commonly held beliefs are difficult to steer through the review process. Editors need to be aware that their own risk aversion may be a main cause for not publishing counterintuitive papers (Staelin, 2005). This paper should encourage editors to take special care of papers that potentially challenge commonly held beliefs and take a stand in favor of such papers when they are attacked by reviewers. At the same time, the reward of increased citations may incentivize scholars to exaggerate the extent to which their paper challenges commonly held beliefs (a tendency we did not control for in the methodology we adopted). Recent integrity cases in 
marketing academia have shown the balance between the interesting and the truth to be of critical importance to the sustainability and credibility of our field. Thus, editors and reviewers should remain cautious about appropriate coverage of the literature and claims of the contribution made by a paper.

Maybe even more so than other papers, this paper has several limitations that may give rise to future research. First, our observation window ends in 2007, which we selected because we wanted papers to have sufficient time (i.e., opportunity) to reveal their citation potential (Van Dalen \& Henkens, 2001).

Second, the results in this study are conditional upon acceptance of an article. Survival bias is unavoidable in citation research of a certain magnitude, given the confidential nature of the review process. If data are made available by journals, it can be of great value to assess how papers that challenge commonly held beliefs fare in the review process, including whether different types of reviewers show different types of responses to such papers.

Third, despite being grounded in well-established theories in philosophy of science, our classification of citation types may mask important nuances within specific types of citation. In particular, review citations may be a heterogeneous category as some review citations may go beyond merely describing and mentioning prior work and, instead, actually use prior work as a prime justification for conducting a new research study. Resources at our disposal limited our ability to refine the coding of review citations.

Fourth, we excluded from our analyses articles without marketing theory, i.e. those of a purely methodological nature. Because there are no theory propositions or findings, such papers cannot challenge prior theories. This focus on theory papers fits Davis (1971) original work. However, it would be interesting to examine differences in the determinants of citations and citation types between purely methodological papers and papers which emphasize theory.

Fifth, negation citations are rare $(0.6 \%$ of all citations), which means that our analysis of the drivers of negation citations is based on a limited sample $(\mathrm{N}=149)$. We estimated several additional models, with more parsimonious specifications, and found no meaningful differences, only some shifts in significance due to the reduced power in the full model. Future research using, for example, in-depth qualitative analyses of negation citations or surveying scholars could help uncover additional insights regarding the drivers of negation citations.

Finally, even though citation types offer rich insights regarding scientific impact, they are still citation counts. Citation counts are only one possible and imperfect measure of an article's impact (Lehmann et al., 2011). In particular, some articles may diffuse through knowledge vehicles other than scholarly cites (e.g. articles whose content is used directly by practitioners, featured in textbooks or media, or used by classroom instructors). Hence, we join scholars before us in the call for a more comprehensive mapping of the dual impact of academic articles in marketing scholarship and marketing practice (Roberts et al., 2014).

We hope our paper leads to a more knowledgeable usage of citation counts. It serves, again, as a reminder that mere citation counts are an imperfect measure of an article's true impact. Comparing articles, or scholars, across domains or across types of research is particularly challenging and should be avoided or done with caution. Authors, reviewers, journal editors and business school administrators should develop practices that offer a more robust assessment of scientific impact.

\section{Appendix. Measuring Challenging Commonly Held Beliefs}

In this Appendix we provide a detailed overview of the approach and scale we used to measure Challenging Commonly Held Beliefs $\left(\mathrm{CCHB}_{\mathrm{ij}}\right)$, i.e. the extent to which an article $i$ published in journal $j$ challenges commonly held beliefs of its audience. We used 8 reflective items in our Challenging Commonly Held Beliefs scale. We built on the original paper by Davis (1971) to specify the domain of the Challenging Commonly Held Beliefs construct and generate these reflective items. We used seven-point Likert scales to indicate the level of agreement of each coder with the included statements (with $1=$ "completely disagree", and $7=$ "completely agree"). The exact items we used were the following:

1. The authors of this paper claim that what is accepted as $\mathrm{X}$ is in reality non-X.

2. The authors of this paper claim that this paper is an attack on what was taken-for-granted.

3. The authors of this paper claim that this paper disconfirms prior beliefs.

4. The authors of this paper claim that this paper disconfirms what has long been thought of as true.

5. The authors of this paper claim that this paper disconfirms what has been traditionally assumed.

6. The authors of this paper claim that this paper shows that what has been traditionally assumed is not true.

7. The authors of this paper claim that this paper shows that what was thought to be true is actually false.

8. The authors of this paper claim that this paper disconfirms wellaccepted assumptions.

Figure A1 displays the training and coding procedure we used to measure challenging commonly held beliefs (which is similar to Yadav 2010).

Figure A1. Training And Coding Procedure.

\begin{tabular}{|l|l|}
\hline $\begin{array}{l}\text { 1. Description of measurement instrument and discussion of examples with } \\
\text { coders }\end{array}$ \\
$\begin{array}{l}\text { 2. Individual coding of training set of nine articles, not belonging to final } \\
\text { sample }\end{array}$ \\
$\begin{array}{l}\text { 3. Calculation of inter-rater agreement on training set of nine articles } \\
\text { 4. Provision of feedback on inter-rater agreement to coders and discussion of } \\
\text { coding experiences }\end{array}$ \\
\hline
\end{tabular}

\begin{tabular}{|c|c|}
\hline \multirow{11}{*}{ 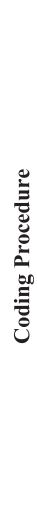 } & 1. Individual coding of articles \\
\hline & $\downarrow$ \\
\hline & 2. Calculation of inter-rater agreement \\
\hline & $\downarrow$ \\
\hline & 3. Selection of $20 \%$ most divergently coded articles \\
\hline & $\downarrow$ \\
\hline & 4. Provision of coding information of most divergently coded articles to coders \\
\hline & $\downarrow$ \\
\hline & 5. Opportunity to individually re-code articles \\
\hline & $\downarrow$ \\
\hline & 6. Calculation of final inter-rater agreement \\
\hline
\end{tabular}

One of the authors first described the measurement instrument above to a team of four research assistants (RAs) and provided examples of articles on both sides of the scale. Next, each RA and one of the authors coded a set of 9 articles that did not belong to our final sample of 659 articles. The mean ICC over all the items was equal to .83 , which is satisfactory. The author also gave feedback to the RAs on the inter-rater agreement for this sample of 9 articles. The RAs shared their coding experiences. 
After this training procedure, each of the four RAs coded half of the 659 articles in a random order. One of the authors coded all of them. In total, this procedure generated three sets of measures for each article in our sample. The mean ICC across all 659 articles over all 8 items was equal to .69. Given this moderate agreement among coders, we followed a Delphi procedure to further improve coding (see Linstone \& Turoff, 2002 ). For the $20 \%$ articles with the highest average deviation across coders across the 8 measurement items, we allowed coders to revise their score after seeing the average score across all coders. After this procedure, the mean ICC across all 659 articles over the 8 items increased to .77 .

We factor analyzed the measurement instrument to assess its validity and reliability. We found that one factor represented the data structure the best. This single factor explained $95.17 \%$ of the total variance. All factor loadings were statistically significant $(p<.01)$ and the lowest factor loading equaled .96 , showing high convergent validity. The Cronbach's alpha was .99, the composite reliability was .99 and the variance extracted was .94 , showing high reliability.

\section{References}

Aaker, D.A., Kumar, V., \& Day, G.S. (2004). Marketing research (8th ed.). John Wiley \& Sons. Abelson, R.P. (1995). Statistics as principled argument. Hillsdale, NJ: Erlbaum.

Abraham, M.M., \& Lodish, L.M. (1993). An implemented system for improving promotion productivity using store scanner data. Marketing Science, 12(3), 248-269.

Anderson, M.H., \& Sun, P.Y.T. (2010). What scholars retrieved from Walsh and Ungson (1991)? A citation context study. Management Learning, 41(2), 131-145.

Baldi, S. (1998). Normative versus social constructivist processes in the allocation of citations: A network-analytic model. American Sociological Review, 63(6), 829-846.

Barber, B. (1961). Resistance by scientists to scientific discovery. Science, 134, 596-602.

Bartunek, J.M., Rynes, S.L., \& Ireland, R.D. (2006). What makes management research interesting and why does it matter? Academy of Management Journal, 49(1), 9-15.

Bauerly, R.J., Johnson, D.T., \& Singh, M. (2005). Readability and the impact of marketing. In: Marketing renaissance: Opportunities and imperatives for improving marketing thought, practice, and infrastructure. Journal of Marketing, 69(October), 19-20.

Baumgartner, H., \& Pieters, R. (2003). The structural influence of marketing journals: A citation analysis of the discipline and its subareas over time. Journal of Marketing, 67(April), 123-139

Berger, J. (2009). Does article order influence citation count? Unpublished Working Paper.

Bergh, D.D., Perry, J., \& Hanke, R. (2006). Some predictors of SMJ article impact. Strategic Management Journal, 27(1), 81-100.

Bettencourt, L.A., \& Houston, M.B. (2001). The impact of article method type and subject area on article citations and reference diversity in JM, JMR and JCR. Marketing Letters, 12(4), 327-340.

Bornmann, L., \& Daniel, H. -D. (2008). What do citation counts measure? A review of studies on citing behavior. Journal of Documentation, 64(1), 45-80.

Borokhovich, K.A., Bricker, R.J., \& Simkins, B.J. (1994). Journal communication and influence in financial research. Journal of Finance, 49(2), 713-725.

Brooks, T.A. (1985). Private acts and public objects - An investigation of citer motivations. Journal of the American Society for Information Science, 36, 223-229.

Cameron, A.C., \& Trivedi, P.K. (1990). Regression-based tests for overdispersion in the Poisson model. Journal of Econometrics, 46(3), 347-364.

Cameron, A.C., \& Trivedi, P.K. (2014). Count panel data. In B.H. Baltagi (Ed.), The Oxford handbook of panel data econometrics. Oxford University Press.

Cano, V. (1989). Citation behavior: Classification, utility, and location. Journal of the American Society for Information Science, 40(4), 284-290.

Case, D.O., \& Higgins, G.M. (2000). How can we investigate citation behavior? A study of reasons for citing literature in communication. Journal of the American Society for Information Science, 51, 635-645.

Chubin, D.E., \& Moitra, S.D. (1975). Content analysis of references: Adjunct or alternative to citation counting? Social Studies of Science, 5, 423-441.

Cole, J.R., \& Cole, S. (1973). Social stratification in science. Chicago, IL: University of Chicago Press.

Colquitt, J.A., \& George, G. (2011). From the editors: Publishing in AMJ - Part 1: Topic choice. Academy of Management Journal, 54(3), 432-435.

Davis, M.S. (1971). That's interesting: Towards a phenomenology of sociology and a sociology of phenomenology. Philosophy of the Social Sciences, 1(4), 309-344.

Dekimpe, M.G. (2009). From the (new) editor. International Journal of Research in Marketing, 26(4), 259-260.

Dekimpe, M.G., \& Hanssens, D.M. (1999). Sustained spending and persistence response: A new look at long-term marketing profitability. Journal of Marketing Research, 36(4), 397-412.

Egghe, L. (2006). Theory and practice of the g-index. Scientometrics, 69, 131-152.

Erdem, T., Swait, J., \& Valenzuela, A. (2006). Brands as signals: A cross-country validation study. Journal of Marketing, 70(1), 34-49.

Frost, C.O. (1979). The use of citations in literary research: A preliminary classification of citation functions. The Library Quarterly, 49(4), 399-414

Garfield, E. (1972). Citation analysis as a tool in journal evaluation - Journals can be ranked by frequency and impact of citations for science policy studies. Science, 178, 471-479.
Garfield, E. (1990). How ISI selects journals for coverage: Quantitative and qualitative considerations. Current Contents, 22(May 28), 5-13.

Goldenberg, J., Lehmann, D.R., \& Mazursky, D. (2001). The idea itself and the circumstances of its emergence as predictors of new product success. Management Science, 47(1), 69-84.

Goldenberg, J., Libai, B., Muller, E., \& Stremersch, S. (2010). The evolving social network of marketing scholars. Marketing Science, 29(3), 561-567.

Griffith, D.A., \& Lusch, R.F. (2007). Getting marketers to invest in firm-specific capital. Journal of Marketing, 71(January), 129-145.

Hanney, S., Frame, I., Grant, J., Buxton, M., Young, T., \& Lewison, G. (2005). Using categorisations of citations when assessing the outcomes from health research. Scientometrics, 65(3), 357-379.

Hidi, S. (1990). Interest and its contribution as a mental resource for learning. Review of Educational Research, 60(4), 549-571.

Hirsch, J.E. (2005). An index to quantify an individual's scientific research output Proceedings of the National Academy of Sciences of the United States of America, 102, 16569-16572

Hirsch, J.E. (2007). Does the h-index have predictive power. Proceedings of the National Academy of Sciences of the United States of America, 104, 19193-19198.

Huber, J. (2008). The value of sticky articles. Journal of Marketing Research, 45(June), 257-260.

Judge, T.A., Cable, D.M., Colbert, A.E., \& Rynes, S.L. (2007). What causes a management article to be cited? Article, author or journal? Academy of Management Journal, 50(3), 491-506.

Kashdan, T.B., \& Silvia, P.J. (2009). Curiosity and interest: The benefits of thriving on novelty and challenge. In C.R. Snyder, \& S.J. Lopez (Eds.), Oxford handbook of positive psychology (pp. 367-374) (2nd ed.) (Ch. 34).

Krampen, G., Becker, R., Wahner, U., \& Montada, L. (2007). On the validity of citation counting in science evaluation: Content analyses of references and citations in psychological publications. Scientometrics, 71(2), 191-202.

Krampen, G., \& Montada, L. (2002). Wissenschaftsforschung in der Psychologie. Göttingen: Hogrefe.

Kuhn, T.S. (1996). The structure of scientific revolutions (3rd ed.). Chicago, IL: The University of Chicago Press.

Kunz, W.H., \& Hogreve, J. (2011). Toward a deeper understanding of service marketing The past, the present and the future. International Journal of Research in Marketing, $28,231-247$.

LaBand, D.N. (1986). Article popularity. Economic Inquiry, 24(1), 173-180.

Lehmann, D.R., McAlister, L., \& Staelin, R. (2011). Sophistication in research in marketing. Journal of Marketing, 75(July), 155-165.

Leonidou, L.C., Katsikeas, C.S., \& Samiee, S. (2002). Marketing strategy determinants of export performance: A meta-analysis. Journal of Business Research, 55(January), 51-67.

Linstone, H. A., \& Turoff, M. (2002). The Delphi method: Techniques and applications. Canada: Addison-Wesley Publishing Company.

Long, J.S., \& Reese, J. (2001). Regression models for categorical dependent variables using stata. College Station, TX: Stata Press Corp.

Mahoney, M.J. (1979). Psychology of the scientist: An evaluative review. Social Studies of Science, 9, 349-375.

Malhotra, N.K., Birks, D.F., \& Wills, P. (2010). Marketing research: An applied approach (6th ed.). Prentice Hall.

Merton, R.K. (1968). The Matthew effect in science. Science, 159(3810), 59-63.

Merton, R.K. (1988). The Matthew effect in science II: Cumulative advantage and the symbolism of intellectual property. ISIS, 79(4), 606-623.

Mingers, J., \& Xu, F. (2010). The drivers of citations in management science journals. European Journal of Operational Research, 205, 422-430.

Moravcsik, M.J., \& Murugesan, P. (1975). Some results on the function and quality of citations. Social Studies of Science, 5(1), 86-92.

Narasimhan, C., Neslin, S.A., \& Sen, S.K. (1996). Promotional elasticities and category characteristics. Journal of Marketing, 60(April), 17-30

Padmanabhan, V., \& Png, I.P.L. (1997). Manufacturer's return policies and retail competition. Marketing Science, 23(4), 614-618.

Peritz, B.C. (1983). A classification of citation roles for the social sciences and related fields. Scientometrics, 5(5), 303-312.

Radicchi, F., Fortunato, S., \& Castellano, C. (2008). Universality of citation distributions: Toward an objective measure of scientific impact. Proceedings of the National Academy of Sciences of the United States of America, 105, 17268-17272.

Rindfleisch, A., Malter, A.J., Ganesan, S., \& Moorman, C. (2008). Cross-sectional versus longitudinal survey research: Concepts, findings and guidelines. Journal of Marketing Research, 45(June), 261-279.

Roberts, J.H., Kayande, U., \& Stremersch, S. (2014). From academic research to marketing practice: Exploring the marketing science value chain. International Journal of Research in Marketing, 31(2), 127-140.

Rossi, P.E., \& Allenby, G.M. (1993). A Bayesian approach to estimating household parameters. International Journal of Research in Marketing, 30(2), 171-182.

Samiee, S., \& Anckar, P. (1998). Currency choice in industrial pricing: A cross-national evaluation. Journal of Marketing, 62(July), 112-127.

Sawyer, A.G., Laran, J., \& Xu, J. (2008). The readability of marketing journals: Are awardwinning articles better written? Journal of Marketing, 72(January), 108-117.

Seggie, S.H., \& Griffith, D.A. (2009). What does it take to get promoted in marketing academia? Understanding exceptional publication productivity in the leading marketing journals. Journal of Marketing, 73(1), 122-132.

Shadish, W.R., Tolliver, D., Gray, M., \& Sengupta, S.K. (1995). Author judgments about works they cite - Three studies from psychology journals. Social Studies of Science, 25, 477-498.

Shrout, P.E., \& Fleiss, J.L. (1979). Intraclass correlations: Uses in assessing rater reliability. Psychological Bulletin, 86(2), 420-428.

Shugan, S.M. (2003). Defining interesting research problems. Marketing Science, 22(1), 1-14 
Small, H. (2004). On the shoulders of Robert Merton: Towards a normative theory of citation. Scientometrics, 60(1), 71-79.

Smith, D.C. (2003). The importance and challenges of being interesting. Journal of the Academy of Marketing Science, 31(3), 319-322.

Staelin, R. (2005). Influencing the practice through big new ideas. In: Marketing renaissance: Opportunities and imperatives for improving marketing thought, practice and infrastructure. Journal of Marketing, 69(October), 19-20.

Stremersch, S., \& Lehmann, D.R. (2009). From the (past) editors. International Journal of Research in Marketing, 26(4), 257-258.

Stremersch, S., \& Verhoef, P.C. (2005). Globalization of authorship in the marketing discipline: Does it help or hinder the field? Marketing Science, 24(4), 585-594.

Stremersch, S., Verniers, I., \& Verhoef, P.C. (2007). The quest for citations: Drivers of article impact. Journal of Marketing, 71(July), 171-193.
Tellis, G.J., Chandy, R.K., \& Ackerman, D.S. (1999). In search for diversity: The record of major marketing journals. Journal of Marketing Research, 36(February), 120-131.

Van Dalen, H.P., \& Henkens, C.J.I.M. (2001). What makes a scientific article influential? Scientometrics, 50(3), 455-482

Vinkler, P. (1987). A quasi-quantitative citation model. Scientometrics, 12, 47-72.

Wang, H. (2004). Do return policies intensify retail competition? Marketing Science, 23(4), 611-613.

Woolgar, S. (1991). Beyond the citation debate: Towards a sociology of measurement technologies and their use in science policy. Science and Public Policy, 18, 319-326.

Wotruba, T.R., \& Tyagi, P.K. (1991). Met expectations and turnover in direct selling. Journal of Marketing, 55(July), 24-35.

Yadav, M.S. (2010). The decline of conceptual articles and implications for knowledge development. Journal of Marketing, 74(January), 1-19. 